\title{
SISTEM MONITORING SCADA TANGKI GULA TETES BERBASIS WIRELESS MENGGUNAKAN PROTOKOL MODBUS TCP/IP
}

\author{
Sukamto ${ }^{1)}$ dan Yohan Intan ${ }^{2)}$ \\ 1,2 Jurusan Teknik, Politeknik Negeri Madiun, Jl. Serayu no. 84, Madiun, 63133 \\ E-mail: ${ }^{1}$ sukamto@pnm.ac.id
}

\begin{abstract}
The molasses monitoring system at sugar factory still uses conventional monitoring by measuring directly on the tank. It is very ineffective because when conducting sale and purchase of molaseses must measure to the tank so that the effectiveness of the sale and purchase transactions is very less.

The purpose of this research to increase sale and purchase eficiency of molasses at sugar factories in the madiun area. One such device is a wireless system that can transmit data from the tank so there is no need to measure the tank in the field. Many devices are used such as access point, receiver, analog input based LAN communication, PT100 temperature sensor, level sensor, etc.

Analog input-based LAN communication is one device that connects between sensors and computers through a LAN network which is then transmitted by access point through wireless signals so that it can be accessed by the receiver remotely without installing cable as far as 300 meters. Data from receiver can be accessed by computer by using visual studio program as SCADA monitoring interface by using TCP / IP modbus protocol. The result of this research can simplify the process of data retrieval from sugar tank in the field.
\end{abstract}

Keywords: SCADA,Modbus TCP/IP,Monitoring System, Wireless

\begin{abstract}
ABSTRAK
Saat ini sistem monitoring gula tetes di pabrik gula masih menggunakan monitoring konvensional dengan mengukur langsung pada tangki tetes. Hal ini sangat tidak efektif karena saat melakukan transaksi jual beli gula tetes harus mengukur terlebih dahulu ke tangki penampungan sehingga efektifitas dari transaksi jual beli sangat kurang.

Tujuan penelitian ini adalah peningkatan sistem pada transaksi jual beli gula tetes pada pabrik gula yang ada di area Madiun. Salah satu perangkat tersebut adalah sistem wireless yang dapat mengirimkan data dari tangki sehingga tidak perlu mengukur tangki di lapangan. Hal tersebut saat ini menjadi salah satu fokus penelitian yang terus dikembangkan. Banyak perangkat yang digunakan seperti acces point, receiver, analog input berbasis komunikasi LAN, sensor suhu PT100, sensor level, dll.

Analog input berbasis komunikasi LAN merupakan salah satu perangkat yang menghubungkan antara sensor dan komputer melalui jaringan LAN yang kemudian di pancarkan oleh acces point melalui sinyal wireless sehingga dapat diakses oleh receiver dari jarak jauh tanpa memasang kabel sejauh 300 meter. Data dari receiver dapat diakses oleh komputer dengan menggunakan program visual studio sebagai interface SCADA monitoring dengan menggunakan protokol modbus TCP/IP. Hasil dari penelitian ini dapat mempermudah proses pengambilan data dari tangki gula tetes di lapangan.
\end{abstract}

Kata Kunci: SCADA,Modbus TCP/IP, Sistem Monitoring, Wireless, Komunikasi

\section{PENDAHULUAN}

Tetes tebu merupakan hasil proses pemisahan larutan dengan kristal gula, yang akan ditampung dalam wadah berbentuk tangki. Tetes tebu dapat dimanfaatkan bahan baku pembuatan spritus, alkohol, MSG (penyedap rasa), kecap dan bahan pencampur makanan ternak. Mengingat banyaknya industri maupun perorangan yang membutuhkan tetes ini maka otomatis mendorong terjadinya transaksi jual beli yang nilainya signifikan. Namun pada saat proses jual beli, pihak dari pabrik gula merasa kurang efektif saat monitoring tangki gula tetes masih dilakukan dengan cara konvensional yaitu petugas harus 
kelapangan untuk mengukur suhu dan level dari tangki tetes. Hal ini menyebabkan proses jual beli memerlukan waktu yang agak lama karena pihak pembeli harus menunggu data dari lapangan sebelum melakukan transaksi kepada pihak pabrik gula.

Untuk meningkatkan proses monitoring tangki diperlukan adanya sistem monitoring scada dari jarak jauh berbasis wireless sehingga monitoring tangki dapat dilakukan di dalam ruangan kantor atau control room sehingga proses jual beli gula tetes dapat dilakukan dengan waktu yang lebih efektif tanpa perlu menunggu petugas yang akan kelapangan untuk mengambil data dari tangki. Hal ini dapat meningkatkan pelayanan kepada pembeli gula tetes karena tidak perlu menunggu terlalu lama saat proses transaksi jual beli sehingga dapat menghemat waktu dan tenaga.

Untuk sistem monitoring scada pada tangki gula tetes dari jarak jauh diperlukan perangkat wireless yang dapat mengirimkan data dari lapangan ke kantor tanpa menggunakan kabel. Hal ini juga sangat menguntungkan untuk pihak pabrik gula karena tidak memerlukan investasi penarikan kabel dengan jarak yang jauh sehingga sistem wireless ini biayanya lebih murah dan handal ketika diaplikasikan.

Dalam penelitian diusulkan menggunakan protokol modbus TCP/IP untuk transfer data dari perangkan analog input ke komputer. Protokol ini sangat baik digunakan karena banyak perangkat analog input yang mendukung sehingga pengambilan data secara real time dapat dibuat dengan menggunakan perangkat lunak visual studio. Sistem akan diimplemetasikan pada miniatur tangki gula tetes yang nantinya dapat diterapkan pada pabrik gula di area Madiun dan Jawa Timur.

\section{METODE PENELITIAN}

Dalam pembuatan sistem monitoring SCADA pada tangki tetes tebu terlebih dahulu melakukan perancangan sistem dan spesifikasi alat. Peralatan yang akan digunakan adalah sensor suhu PT100 dan sensor level yang digunakan sebagai indikator dari level tebu pada tangki. Keluaran dari sensor level berupa tegangan $0-5$ Volt dan sensor suhu berupa resistansi yang akan ditambahkan rangkaian sehingga output sensor suhu berupa tegangan $0-5$ Volt. Kemudian membutuhkan peralatan Analog Input sebagai masukan dari sensor yang mana dapat merubah data analog menjadi data digital (ADC), perangkat ini menggunakan MOXA analog input yang mendukung komunikasi LAN sehingga data dari sensor dapat diakses menggunakan jaringan LAN menggunakan protokol modbus TCP/IP. Untuk menghubungkan antara komputer dan analog input dari jarak jauh diperlukan perangkat wireless sebagai media transfer data tanpa menggunakan kabel, Acces Point dipasang pada sisi tangki yang dihubungkan dengan modul analog dari Moxa menggunakan kabel LAN yang kemudian akan dipancarkan dengan SSID yang sudah disetting, kemudian pada sisi ruangan kantor digunakan receiver sebagai penerima data dari acces point dengan menyamakan SSID yang telah disetting sebelumnya dan dihubungkan ke komputer menggunakan kabel LAN.

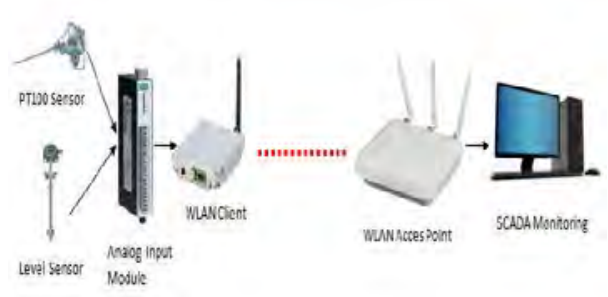

Gambar 1. Rancangan Hardware Monitoring Tanki dengan Wireless 
Dalam sistem yang dirancang terdapat beberapa perangkat keras penyusun, diantaranya adalah :

PT100 Sensor, merupakan sensor temperatur yang terdiri dari suatu komponen yang dapat mengubah besaran panas menjadi besaran listrik sehingga dapat mendeteksi gejala perubahan suhu pada obyek tertentu. Gambar 2. menunjukkan sensor tersebut.

a.

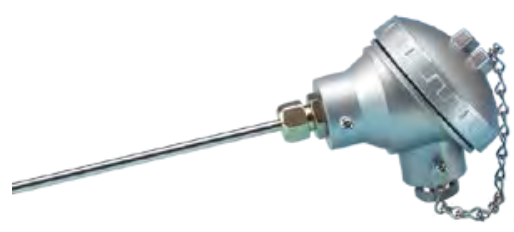

Gambar 2. Sensor Temperatur PT100 (Sumber : https://www.tcdirect.co.uk/ Default.aspx?level=2\&Department_id=230)

b. Level Sensor Merupakan sebuah sensor yang digunakan untuk mengetahui ketinggian cairan. Dalam aplikasi pengukuran level fluida pada tangki, Plat pertama adalah Probe yang dimasukkan ke dalam tangki, sedangkan dinding tangki akan berfungsi sebagai Plat kedua dimana jarak antara probe dengan dinding tangki tidak akan berubah maka satusatunya parameter yang akan berubah adalah konstanta dielektrik. Udara memiliki konstanta dielektrik satu sedangkan fluida memiliki konstanta dielektrik lebih dari satu.

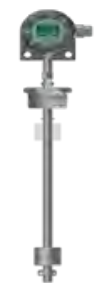

Gambar 3. Level Sensor

(Sumber : https://fpisensors.com/continuouslevel-sensors/)

c. Analog Input Modul, merupakan sebuah peralatan sebagai masukan dari sensor yang mana dapat merubah data analog menjadi data digital (ADC). Modul ini dapat langsung diakses menggunakan ethernet sehingga pengambilan data dari sensor dapat di kirim menggunakan WLAN Client.

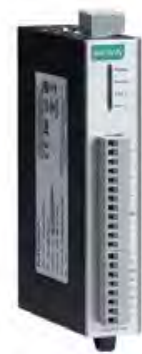

Gambar 4. Moxa IoLogic 1240 sebagai analog input

(Sumber : https://www.moxa.com)

d. WLAN Acces Point, merupakan sebuah alat yang berfungsi untuk menyambungkan alat-alat wireless ke sebuah jaringan berkabel (wired network) menggunakan wifi, bluetooth dan sejenisnya. Wireless Access Point digunakan untuk membuat jaringan WLAN (Wireless Local Area Network) ataupun untuk memperbesar cakupan jaringan wifi yang sudah ada (menggunakan mode bridge). Access Point merupakan titik pusat jaringan wireless, alat ini memancarkan frekuensi radio untuk mengirimkan dan menerima data. Fungsi Wireless Access Point ini kira-kira sama dengan switch / hub dalam jaringan kabel yang memungkinkan banyak client terhubung ke jaringan.

e.

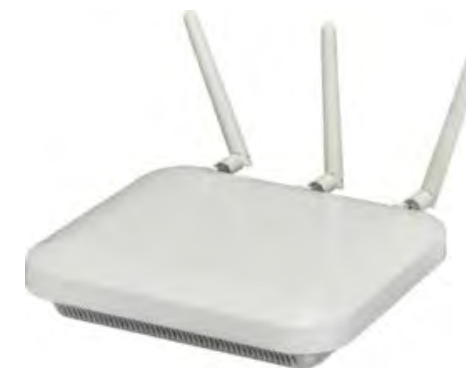

Gambar 5. Wireless Acces Point

(Sumber : http://www.tp-link.co.id)

f. Wireless Client, merupakan client / device yang menerima sinyal / frekuensi yang dipancarkan dari wireless access point, seperti $\mathrm{Wi}-\mathrm{Fi}$, Bluetooth. Yang tentunya frekuensi dari pemancar dan yang menerima sama. 


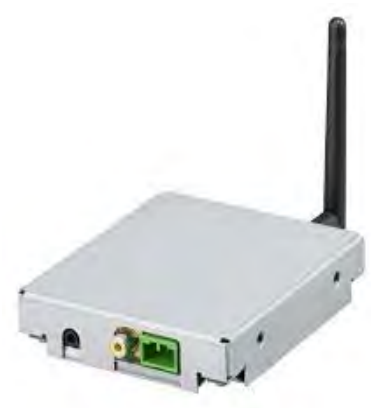

Gambar 6. Wireless Client

(Sumber : http://www.tp-link.co.id)

Sedangkan perangkat lunak penyusun sistem yang digunakan adalah menggunakan VB.NET yang merupakan sebuah bahasa pemograman dan sebagai sarana (tool) untuk menghasilkan program-program aplikasi berbasiskan windows. projek pada VB.NET terdiri dari satu form dan satu modul. Class ModbusTCP sebagai sub class yang berisi protokol dari modbus TCP/IP yang akan digunakan sebagai interface komunikasi antara VB dan perangkat keras, dan semua objek di frmStart digunakan sebagai tampilan dari monitoring yang berisi level ketinggian cairan gula tetes pada tangki dan suhu pada tangki di setiap level.

Setiap data dari sensor memiliki alamat input register masing-masing yang akan diakses melalui modbus TCP/IP sehingga data yang akan diambil oleh VB.NET akan sama dengan data dari sensor yang ada di lapangan. Pada sisi interface software terdapat button connect yang akan menghubungkan antara komputer dan perangkat keras dengan IP Adress yang sudah ditentukan apabila IP komputer tidak sama dengan perangkat keras maka program tidak akan jalan, dan untuk memutus komunikasi terdapat button disconnect.

Gambar 7 adalah desain dari SCADA monitoring untuk tangki gula tetes pada pabrik tebu :

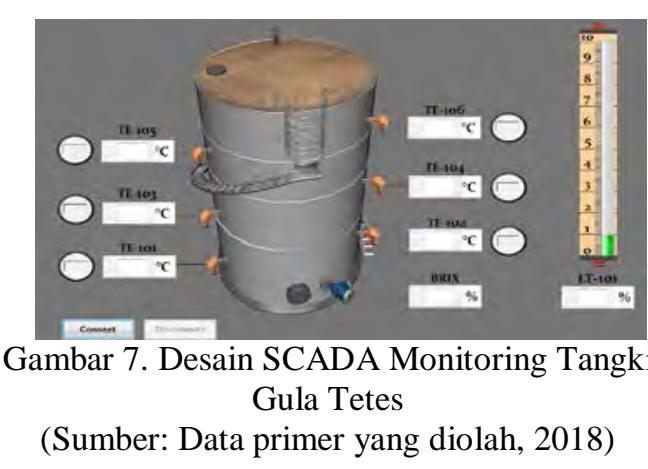

\section{HASIL DAN PEMBAHASAN}

Hasil dari penelitian ini dapat dilihat pada gambar 8 yaitu sebuah prototype sistem monitoring scada tangki gula tetes. Prototype sistem yang telah dibuat kemudian akan dilakukan pengujian untuk mengetahui apakah sistem ini dapat bekerja dengan baik sesuai dengan tujuan yang diharapkan.

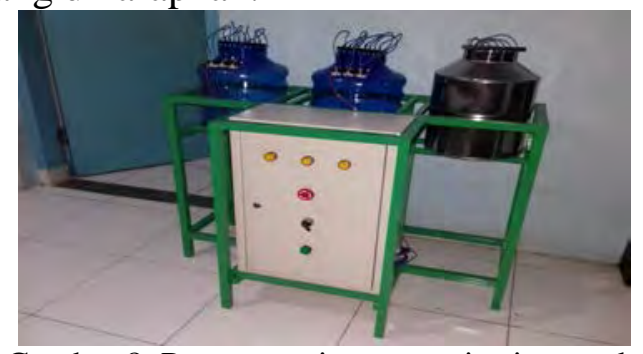

Gambar 8. Prototype sistem monitoring scada tangki gula tetes

(Sumber: Data primer yang diolah, 2018)

Gambar 9 menunjukan rangkaian panel kontrol yang digunakan pada sistem monitoring scada tangki gula tetes ;

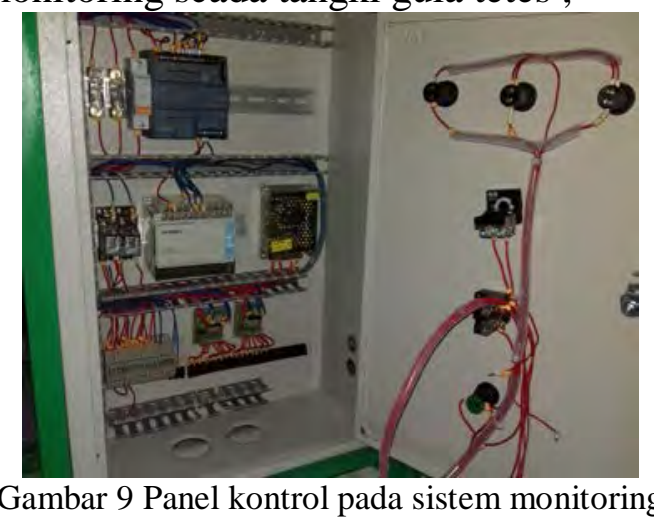

(Sumber: Data primer yang diolah, 2018)

Pengujian terhadap sistem monitoring ini meliputi pengujian sensor suhu, pengujian sensor level dan pengujian jarak wireless. Hasil dari pengujian ini dapat dilihat pada tabel 1 , tabel 2 dan tabel 3 berikut : 
Tabel 1. Pengujian sensor suhu

\begin{tabular}{|l|c|c|c|}
\hline \multicolumn{1}{|c|}{$\begin{array}{c}\text { Pengujia } \\
\text { n }\end{array}$} & $\begin{array}{c}\text { Senso } \\
\text { r } \\
\text { Suhu }\end{array}$ & $\begin{array}{c}\text { Thermomete } \\
\text { r }\end{array}$ & $\begin{array}{c}\text { Erro } \\
\text { r }\end{array}$ \\
\hline $\begin{array}{l}\text { Taangki di } \\
\text { isi air }\end{array}$ & 25,9 & 26,6 & $2.6 \%$ \\
\hline $\begin{array}{l}\text { Tangki di isi } \\
\text { air gula }\end{array}$ & 27,8 & 28,4 & $2.1 \%$ \\
\hline $\begin{array}{l}\text { Tangki tanpa } \\
\text { isi }\end{array}$ & 29,5 & 30,1 & $2 \%$ \\
\hline
\end{tabular}

Sumber : Data Sekunder yang diolah, Tahun 2018

Tabel 2. Pengujian sensor Level

\begin{tabular}{|l|c|c|c|}
\hline \multicolumn{1}{|c|}{ Pengujian } & $\begin{array}{c}\text { Sensor } \\
\text { Level }\end{array}$ & $\begin{array}{c}\text { Pengukuran } \\
\text { Manual }\end{array}$ & Error \\
\hline $\begin{array}{l}\text { Tangki di isi air } \\
1 / 4\end{array}$ & 10,3 & 10,1 & $1.9 \%$ \\
\hline $\begin{array}{l}\text { Tangki di isi air } \\
1 / 2\end{array}$ & 15,6 & 15,2 & $2.6 \%$ \\
\hline $\begin{array}{l}\text { Tangki di isi air } \\
\text { 3/4 }\end{array}$ & 20,7 & 20,4 & $1.5 \%$ \\
\hline Tangki tanpa isi & 0 & 0 & 0 \\
\hline
\end{tabular}

Sumber : Data Sekunder yang diolah, Tahun 2018

Tabel 3 Pengujian jarak wireless

\begin{tabular}{|l|c|c|c|}
\hline Pengujian & $\begin{array}{c}\text { Di Dalam } \\
\text { Ruangan }\end{array}$ & $\begin{array}{c}\text { Beda } \\
\text { Ruangan }\end{array}$ & $\begin{array}{c}\text { Di Luar } \\
\text { Ruangan }\end{array}$ \\
\hline Jarak 1m & oke & oke & oke \\
\hline Jarak $5 \mathrm{~m}$ & oke & oke & oke \\
\hline Jarak 10m & oke & oke & oke \\
\hline Jarak 20m & - & oke & oke \\
\hline Jarak 50m & - & oke & oke \\
\hline Jarak 100m & - & - & oke \\
\hline Jarak 200m & - & - & - \\
\hline
\end{tabular}

Sumber : Data Sekunder yang diolah, Tahun 2018

Dari hasil tabel hasil pengujian dapat kita lihat, untuk pengujian sensor suhu diperoleh hasil yang lebih rendah dibanding hasil pengukuran manual yaitu menggunakan thermometer. Hal ini bisa diakibatkan oleh pengaruh sensitifitas dari sensor sendiri. Error yang didapatkan masih masih dalam batas toleransi yang diijinkan yaitu dikisaran $2 \%$. Untuk pengujian sensoran sensor level, hasil yang diperoleh lebih tinggi bila dibanding dengan pengukuran manual menggunakan penggaris. Hal ini bisa diakibatkan oleh kurang presisi nya (datar) tempat untuk meletakan tangki. Error yang didapatkan juga masih dalam batas toleransi dikisaran 2 \%. Sedangkan untuk pengujian wireless masih bisa dikatakan berhasil meskipun jarak terjauh untuk diluar ruangan hanya $100 \mathrm{~m}$.

\section{KESIMPULAN}

Dari hasil penelitian tentang sistem monitoring scada tangki gula tetes berbasis wireless, dihasilkan berupa prototype yang diharapkan bisa aplikasikan secara real dilapangan sehingga tujuan penelitian untuk mempermudah pada saat transaksi gula tetes tercapai. Operator tidak perlu bolak balik ke lapangan, namun cukup di control room sehingga bisa menambah efisiensi waktu transaksi.

\section{DAFTAR PUSTAKA}

[1] Bailey, David. Wright, Edwin, (2003) "Practical SCADA for Industry" Great Britain : Elsevier.

[2] User's Manual Book LG "Programmable Logic Controller GLOFA GM7 Series LG” Industrial Systems

[3] Bayu, Aji H, (2009) "Sistem Monitoring pada Stasiun Pompa Air Bersih Menggunakan SCADA WonderWare dan PLC LG MasterK120S”, Laporan Tugas Akhir Teknik Elektro Politeknik Negeri Jakarta

[4] Lidya Boniphatia Sinaga, Winda Wijayanti, (2011) "Sistem Monitoring Miniatur Water Level Control Dengan Scada Wonderware Dan PLC Glofa”, Tugas Akhir Program Studi Elektronika Politeknik Negeri Batam

[5] Farid Hidayat, (2016) "Sistem Scada Untuk Kontrol Dan Monitoring Level Air Pada Pintu Air Untu Meningkatkan Kewaspadaan Banjir”, Undergraduate thesis, Universitas Narotama.

[6] Dani Usman, (2018) "Sistem Komunikasi Sensor Jamak Pada Jaringan SCADA Berbasis RS-485”, Jurnal Rekayasa Teknologi dan Sains Terapan Vol.1, No.2 Oktober 2018 ISSN 2621-2714. 
Sukamto dan Yohan Intan. Sistem Monitoring SCADA... 